
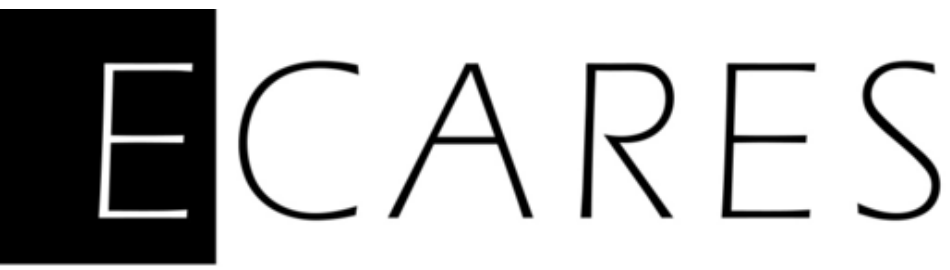

\title{
Local Search Markets and External Competition
}

Patrick Legros

Université libre de Bruxelles (ECARES), Northeastern and CEPR

Konrad Stahl

University of Mannheim, CEPR, CESifo and ZEW

May 2019

ECARES working paper 2019-13

ECARES

ULB - CP $114 / 04$

50, F.D. Roosevelt Ave., B-1050 Brussels BELGIUM

www.ecares.org 


\title{
Local Search Markets and External Competition*
}

\author{
Patrick Legros ${ }^{\dagger}$ and Konrad Stahl ${ }^{\ddagger}$
}

April 29, 2019

\begin{abstract}
Increased competition tends to benefit all buyers with increasing product variety and decreasing prices. However, if local and external market channels compete for the same class of products, increased competition from the external market crowds out local variety. Under local monopoly, local buyer surplus co-moves with external buyer surplus. Under local free entry oligopoly, buyer surplus is U-shaped. If buyer surplus in the external market is low, local surplus is better provided by local oligopoly, but moves against external surplus; if it is high, local and external surplus co-move, and local surplus is better provided by local monopoly.
\end{abstract}

JEL Classification Numbers: D83, L12, L13, L81.

Keywords: Global competition, Monopoly, Oligopoly, Search

\section{Introduction}

Firms selling on Amazon Market Place face internal competition from other firms on the site, but the number of buyers who visit that site at any given time is influenced by the attractiveness of other platforms like eBay or Yahoo. Bookstores in a town center compete against each other, but the number of buyers who visit the town center is a function of the attractiveness of internet stores. In these examples, internal competition reflects the usual idea that the local firms' residual

\footnotetext{
*We thank participants at seminars and workshops at Berlin, Bonn, ECARES, Lausanne, Mannheim, Toulouse, University College London, and Universities of Rotterdam and Tel Aviv, and in particular Yossi Spiegel for useful comments on an earlier version of the paper. An early version of the paper was circulated as a working paper entitled "Global Competition and Local Markets". Legros gratefully acknowledges financial support of the European Research Council Advanced Grant 339950, and Stahl acknowledges support from Deutsche Forschungsgemeinschaft (CRC TR 224).

${ }^{\dagger}$ Université Libre de Bruxelles (ECARES), Northeastern University and CEPR.

$\ddagger$ University of Mannheim, CEPR, CESifo and ZEW.
} 
demand is a function of strategies followed by other firms in the local market; by contrast, external competition reflects competition exerted by a geographically or technically distant market in which eventually the very same commodities are sold. Firms often face these two types of competition, internal and external. In many cases, however, the local firm ignores the effect of its actions on the redistribution of buyers between the two markets.

The interaction between internal and external competition is not often incorporated in theoretical models of industrial organization. This makes it difficult to appreciate the effects of external competition on standard variables such as the variety of products offered locally and prices charged. Indeed, the interaction between internal and external competition may be key to understanding the performance of different local market structures. For instance, internal competition would suggest that oligopolies perform better in terms of consumer surplus than a monopoly does. But a local monopoly may be able to better fight against external competition, potentially overturning the benefit from local oligopolistic competition. In other words, the performance of different market structures may depend on their ability to internalize, and correct for, the effects that internal competition has on attracting consumers to the market, that is on their ability to fight against external competition.

Related to this, interesting policy questions emerge, especially related to competition policy: Should one allow for mergers - in the extreme: a merger to monopoly - in the face of increasing external competition, e.g., with increasing globalization or with increasing attractiveness of online markets?

We show in this paper that the forces highlighted above give rise to robust effects. We give clear cut conditions under which a monopoly reacts less well vs. reacts better to increasing external competition in terms of consumer surplus and welfare than a free entry oligopoly. The results vary with the intensity of external competition. In particular, once external competition is sufficiently strong, that is the external market (like Yahoo or Amazon's online sales of books) is sufficiently attractive to consumers, multi-product monopoly Pareto dominates free entry oligopoly.

In the model presented below, we concentrate on a trade-off that appears particularly relevant in the interaction between local and internet markets, namely superior inspection possibilities open in 
the local market vs. lower prices in the internet market. Our model involves the Vickrey-Salop circle as the local market whose attractiveness to the typical buyer depends on the number of variants she can select from, as well as the prices quoted alternatively by a multi-product monopoly with an endogenously determined set of products, and an oligopoly of specialized sellers, the number of which is determined by the incentive to enter (or exit) the market. The external market is modelled as an outside option to the typical buyer, that is characterized by an expected indirect utility.

Before patronizing the local market, the typical buyer is imperfectly informed about the best match available to her. Yet she is assumed to know how many variants of the differentiated product are offered locally, which implies that the match quality expected by her increases in the number of variants. We employ a simple search cost structure which approximates reality in a great number of cases. While there is a fixed relative cost of accessing the local vs. the external market, searching in the local market is costless. ${ }^{\square}$ We juxtapose local market reactions to increased external competition under the two market structures with respect to the varieties offered and prices charged.

In our base model, we focus on ex-ante competition between the two markets, that involves the typical buyer's choice to patronize one of the two markets and buy the best alternative available in there. In an extension, we allow in addition for ex-post competition in the particularly relevant sense that the buyer exploits on the superior local inspection possibilities, but then arbitrages between the two markets by buying the selected commodity variant more cheaply in the external market.

We characterize the equilibria arising under the two market structures, and compare the welfare arising in them under different levels of the outside option as varying, e.g., with the intensity of competition in the external market. Starting with the base version of the model involving only $e x$ ante competition, let this option be of low value, so that the share of demand captured by the local market is large. Then local multi-product monopoly acts as if it faced a captive market, and tends to offer a relatively small number of varieties at prices determined myopically, i.e., disregarding the effect of price setting on the attraction of custom to the local market. Under oligopoly, the number of local firms - and thus varieties - will be large and local prices competitive, hence lower than the myopic monopoly price. With this, local buyers tend to be better off under local oligopoly than

\footnotetext{
${ }^{1}$ This is a version of the one-stop shopping technology introduced by Stahl (1982).
} 
under local monopoly, when the outside option offered by the external market is not very valuable.

Now, let the value of the outside option increase. It turns out that the firms acting within the two market structures respond with stark differences: While the number of local varieties decreases under both local monopoly and oligopoly, local buyer surplus increases under monopoly, yet decreases under oligopoly. The reason is that under monopoly, myopic prices decrease with an increase in the value of the outside option and, in terms of buyer surplus, the price decrease more than compensates the reduction in variety. By contrast, under oligopoly, the reduction in local competition leads prices to increase.

We demonstrate the existence of a cut-off level such that if the value in the outside option increases beyond that, the free entry oligopoly and the multi-product monopoly co-move in providing more surplus to local consumers in reaction - with the free entry oligopoly consistently providing less surplus so that the multi-product monopoly Pareto dominates the free entry oligopoly.

These results change drastically when we add ex-post competition opened by the possibility that identical commodities are offered in both markets. When the local firms' pricing decisions are constrained by the prices at which their products are offered in the external market, the free entry oligopoly performs better than the multi-product monopoly. However, that arbitrage option between the two markets is open only when the commodities offered in both markets are standardized.

With this analysis, we can provide clear cut answers to the questions raised above; in particular to a long standing debate in competition policy, about how to react with merger policy to increased global competition. Our answers differ between broad classes of commodities. Our analysis suggests that when the commodities offered are non-standardized, competition policy makers should beware of accepting mergers in the face of low global competition, but should be lenient towards merger when global competition is intense. By contrast, when standardized commodities are offered in both markets, the price pressure exercised by the external market forces the local free-entry oligopoly to perform better than the multi-product monopoly. In this case, merger attempts should not be implemented from a social policy point of view.

Furthermore, we contribute to theory by offering a tractable model of multi-product monopoly 
involving horizontally differentiated products. Our model allows for an endogenous determination of the number of products - an aspect that turns out to be particularly relevant when, as in the present case, evaluating the effects of different market structures.

The remainder of the paper is structured as follows. We will next review the relevant literature. Our model is described in section 2 and analyzed in Section 3 where we develop the relevant comparative statics under local multi-product monopoly and under free entry oligopoly. We extend the basic model in section 4, by allowing consumers to first go to the local market and learn about the best variety offered there, and then go and buy this variety on the external market. In this extension we restrict attention to the local multi-product monopoly and show that the crowding effect is still present when the outside option is of low value. If the outside option is large enough, however, the multi-product monopoly may increase the number of varieties in response to an increase in the value of the outside option, especially if that latter increase is generated by more varieties available in the external market, or else it is easier to inspect such varieties therein. We conclude in section 5. All proofs not offered in the text are available in the Appendix.

\section{Literature Review}

We touch on many literatures, related to the conceptualization of search and product differentiation, to multi-product monopoly, comparisons of market outcomes from monopoly and oligopoly, and to platform economies. We apologize for reporting only on material directly related to what we do, first on papers we rely on in developing our model, then on papers involving similar or complementary modelling efforts and results, and finally on papers involving empirical results that are related to ours.

We borrow our setup from Salop ([979)'s path breaking work, but use more general, concave rather than linear single peaked preferences, and add imperfect ex ante information of buyers about the match value that can be obtained in the local market. In our model, buyers search for the best alternative. The local market is attractive because buyers benefit from reductions in search and inspection costs when many product variants are offered in one market place. We take this approach to modelling local demand from Stahl (1982) and Schulz and Stahl (1996). In these papers, the 
number of products was held exogenous. We endogenize that choice by the multi-product monopoly or in the oligopoly via free entry, and add comparative statics with respect to an outside option. Wolinsky (11984) also uses the Vickrey-Salop circle to model product differentiation in an oligopoly when consumers are imperfectly informed about the available product variants. He assumes prices to be exogenous and welfare evaluates the number of variants offered in a free entry oligopoly, whence we compare the performance of such an oligopoly with that of a multi-product monopoly. ${ }^{\square}$

The number of goods offered within a horizontal differentiation framework can be considered an index of expected quality offered in the market. ${ }^{\mathbf{3}}$ A classic on the quality offered by a monopoly is by Spence (1975). While in his model, the monopoly provides quality by comparing the marginal consumer's valuation of a unit of quality to its marginal cost, the welfare maximizer compares the average consumer's valuation to that cost. Since in our model the average consumer's valuation is higher than the marginal consumer's valuation of quality, the monopoly tends to under-supply quality. Yet unlike Spence's our focus is on the comparison of quality supplied by specialized oligopolists to that under multi-product monopoly. Anderson and Renault (20106) focus on a single product monopolist's advertisement of price and match value. While their setup is very different from ours, their model features parallels to our model that we will reflect upon in its presentation.

As to comparing two market channels, Deneckere and Rothschild (11992) also consider competition à la Vickrey-Salop which they dub local, and competition à la Chamberlain which they dub non-local. Whereas our interest is in analyzing the effects of competition between such two types of markets, their interest is in (welfare) comparing the free entry equilibria evolving independently in the two. Similarly, Anderson and De Palma (2000) compare the outcomes of local competition between neighbors in the Vickrey-Salop model dubbed local, with those of competition between

\footnotetext{
${ }^{2}$ Our work does not relate directly to the recent surge of papers on search. To exemplify, Rhodes (2015) focuses on a seller's pricing decisions when offering a given set of products to vertically differentiated multi-product buyers. His results are driven by changes in the composition of buyers patronizing the market. We focus on the horizontal differentiation of single product buyers and on endogenizing the number of products offered by the monopolist vs. the free entry of single product oligopolists. Zhonl (2014) finds that larger firms charge lower prices which is akin to our result when competition from the external market is strong, but the product bundle offered by these sellers is again exogenous, whence it is endogenous in our model, thus opening a new trade off in the seller's choice. The only paper known to us in which the typical firm chooses its offer of horizontally differentiated products is Rhodes and Zhoul (2016). However, they look at the formation of market structure rather than competition between two market channels.

${ }^{3}$ More precisely, in our search context, the match quality expected by the typical consumer increases.
} 
non-neighboring firms such as in CES type models dubbed global. They aim at integrating the two forms of competition within one unifying model, whereas we emphasize their strict separation, and indeed, the competition between the two. Also within a discrete choice model, Chen and Riordan (20108) show that symmetric duopoly prices may be lower or higher than the single-product monopoly price. Neither of these authors develops a model of multi-product monopoly and compares the outcome with that under oligopoly involving specialized sellers, which strikes us as more appropriate when comparing different forms of competition.

Balasubramanian (1998), and in particular Bouckaert (2000) are closer to what we do. Both model competition between mail order and conventional retailing. Bouckaert adds a monopolistic mail order business to Salop's framework, and compares equilibria involving a local oligopoly with and without a mail-order business. Here, an increase in the value of the outside option provided by the mail order retailer soaks off marginal consumers located equidistantly between the oligopolists along the Vickrey-Salop circle, resulting in a smaller number of retailers. In our model, because consumers don't know what they exactly get (in the local market), such an increase soaks off the average consumer from the local market.

Finally, there are recent contributions to modelling horizontally differentiated multi-product firms by Armstrong and Vickers (2018) and Nocke and Schutz (2018). They differ substantially from ours. While the authors of both papers concentrate on pricing decisions involving a given number of variants offered by the typical firm, our focus is on endogenizing the number of variants sold by the multi-product monopolist and the ensuing consequences on demand and equilibrium prices.

We were surprised not to find more empirical evidence on the effects of channel competition. A likely reason for that is that towards an empirical analysis one needs to combine comparable data sets from rather diverse sources. There are empirical studies that consider the effect of competition between mail order and local retailing (Michaell, 1994), competition between a national chain and local retailers (Jia, 2008, George (200.9)) or more recently, of the channel competition we address specifically (Brynjolfsson and Smith, 2000, Forman et al, 2009, Brynjolfsson et al., 2009, and Pozzil (2013)). Michael (10994) looks at the consequences of the evolving mail-order business on local 
retailing and shows that mail order business efficiently intruded regions with low consumer densities. Jia (2008) shows that Wal-Mart's expansion from the late 1980s to the late 1990s explains roughly 50 percent of the net change in the number of small local discount retailers. George (20)!9) shows that media innovations that can be better exploited by national rather than local beer producers lead to a substantial reduction in the number of local producers, an effect arising in the oligopoly version of our theoretical model. A similar effect is shown by Pozzil (2013), here of increased online offers on brick-and-mortar stores.

Brynjoltsson and Smith (2000) show that prices for standardized goods are 9 - 16 percent lower in internet as compared to brick-and-mortar markets. Forman et al. (201)9) show that distance to the local store matters in online purchasing, and distance mitigates online price effects. Furthermore, the breadth of a product line at a local retail store appears not to affect local purchases. Finally, Brynjoltsson et al. (200.9) emphasize differences in the selection of products between internet, catalog, and local market channels and competition between those. While competition for mainstream products appears to be severe between internet and local markets, competition for niche products between these channels appears to be less intense, but more intense between catalog and brick-and-mortar sellers. We directly relate to these empirical results in Section 4 .

\section{Model}

The local product market consists of the circumference of a Vickrey-Salop circle of unit length. A number $m \geq 1$ of varieties (treated later as a continuous variable) are offered thereon. The number $m$ is observed by the buyers before they decide which market to patronize, the local vs. the "external" market. In the baseline model, the (expected) utility they obtain from patronizing the external market is summarized by an exogenous level $u$. Later on, we decompose that $u$ into components that reflect improvements w.r.t. search costs and search results, vs. improvements resulting from lower prices at which goods are offered in the external market.

The typical buyer (she) has costs of accessing each market. We denote by $\theta$ the relative cost of accessing the external market. $\theta$ has a continuously differentiable log-concave distribution $G$ with 
support on $\mathbb{R}$ and continuous density $g$. Hence, when $\theta$ is negative, the buyer has a relatively lower cost of accessing the external market and when $\theta$ is positive, she has a lower cost of accessing the local market. We denote by $\ell$ the likelihood ratio $g / G$. Log-concavity of $G$ implies that $\ell(\theta)$ is a decreasing function.

The buyers have preferences for different varieties that they learn once they actually shop, that is once they are in the market and can sample the varieties offered therein. We model this by assuming that buyers, while knowing where varieties are located on the Vickrey-Salop-circle, view their best match as a random variable that is uniformly distributed on this circle. Alternatively, one could imagine that the typical buyer knows her ideal variant but, while knowing that $m$ variants are offered and rationally expecting their distribution to be uniform, does not know the location of the typical variant.

With $m$ varieties symmetrically located on the circumference of the circle, the typical buyer anticipates, before going shopping, that her ideal variety will be located at a point $z$ on the circle. If the buyer purchases a variety located at a distance $x$ from her ideal variety, she obtains utility $h(x)$, which we assume to be a decreasing and concave function of $x$. Assuming that all varieties have the same price, the buyer will purchase the variety closest to her ideal one.

Since there are $m$ varieties equally spaced on the circle, varieties are located at points $i / m, i=$ $1, \ldots, m$. If the ideal variety is located on the arc $\left(\frac{i}{m}-\frac{1}{2 m}, \frac{i}{m}+\frac{1}{2 m}\right)$, the buyer purchases from the variety $i$, and has a benefit of $h(|z-i / m|)$. Alternatively, denoting by $i(z)$ the variety closest to $z$, and by $x=|z-i / m|$ the difference between the typical agent's ideal variety and the one consumed, the maximum expected benefit from shopping is

$$
\begin{aligned}
v(m) & =\int_{0}^{1} h(|z-i(z) / m|) d z \\
& =2 m \int_{0}^{1 / 2 m} h(x) d x .
\end{aligned}
$$

We assume that buyers rationally expect the equilibrium price prevailing in the local market. For a given such price $p$ of the typical variety, the buyer type $\theta$ indifferent between buying in the external and the local market is specified by $v(m)-p-\theta=u$, that is $\theta(m, p, u)=v(m)-p-u$. 
The demand thus specified can be served locally within two market structures: A multi-product monopoly deciding about all varieties locally available, and an oligopoly, with each of the firms offering one of the varieties, so the number of varieties offered in oligopoly is determined by free entry into the local market. In both market structures, offering an additional variant involves a fixed cost $F>0$, and a variable cost normalized to zero. In spite of evidence to the contrary we keep the cost structures identical across the two market structures, in order to isolate the comparative static effects we have in mind. We finally assume that $h(1 / 2)>F$. As will become obvious later, this implies that a one-product monopolist can profitably produce when charging a market covering price $p=h(1 / 2)$.

The driving questions in our analysis are whether increasing external competition enhances or reduces local variety, and leads to decreasing or increasing local prices. Yet it is even more informative to ask whether increasing buyer utility $u$ provided in the external market corresponds to increasing or decreasing utility provided locally, and which market structure is better at doing so. ${ }^{\text {田 }}$

Let us briefly relate our model specification to the examples given in the introduction. Closest is the competition between internet and brick-and-mortar markets. However, with the model we also proxy competition between platforms, with the performance of one platform modelled explicitly, and that of its competitor as an outside option to the typical consumer. We relate back to this aspect in the last section of our article when interpreting our results within the policy context.

\footnotetext{
${ }^{4}$ The firms' choices we discuss here are well reflected in both everyday experience. In particular, buyers very often have rough estimates about the number of variants (e.g. shoes) available in a particular market place. Furthermore, prices are not frequently announced: Anderson and Renault (2006) report on several studies according to which pricing information was given only in a fraction of advertising cases they discuss. In our multi-product monopoly case, our index $m$ corresponds to Anderson and Renault (2000)'s expected match value, thus providing a micro-foundation for their index. In our oligopoly case, however, that indication of the attractiveness of the local marketplace is obviously affected by the individual firm's entry decision. In regard to Johnson and Myatt (2006), a change in that index involves a demand shift rather than a rotation in the demand function that would be induced by consumer self-selection.
} 


\section{Comparing Oligopoly and Monopoly}

In this section, buyers decide on the market to shop having only information on the number of varieties present in the local market, and the firms charge prices that maximize their profit, given the consumers have arrived in the local market. The timing of events unfolds as follows:

- The number $m$ of varieties is determined in the local market and observed by buyers

- Buyers form rational expectations about the local prices and decide whether or not to patronize the local market

- Local demand is realized, firms set prices, and buyers decide which variety to buy.

\subsection{Monopoly}

Recalling that the local monopolist enjoys a captive clientele, he trivially avoids inter-variety competition; if he did not and charged a price $p<h(1 /(2 m))$ given he offers $m$ variants, he could profitably increase the price level without losing custom. He therefore chooses a price $p \geq h(1 /(2 m))$. By contrast, if he would choose $p>h(1 /(2 m))$, he would serve consumers who are at most at a distance $h^{-1}(p)<1 /(2 m)$ from the closest variety on the Vickrey-Salop circle, so that the market would not be covered. It turns out that this will never be the case. Hence our multi-product monopolist avoids cannibalization something that a free entry oligopoly will not be always able to do. The result is summarized in

Lemma 1. At given number $m$ of variants offered by the multi-product monopolist, the monopolistic optimum involves a price $p(m)$ such that the market is just covered, so that

$$
p(m)=h(1 /(2 m))
$$

For convenience, we will refer to $h(1 /(2 m))$ as the covering price.

Given the typical buyer rationally expects that price to obtain under monopoly, the surplus to 
the buyer of patronizing the local market before access costs is

$$
H(m) \equiv v(m)-h(1 / 2 m)
$$

As the number of varieties increases, this net value to consumers decreases at a decreasing rate.

Lemma 2. $H(m)$ is a convex and decreasing function of $m$.

The buyer decides to shop in the local market if $H(m) \geq u+\theta$. Thus, the market demand faced by the monopolist is $G(H(m)-u)$, and its profit when choosing $m$ varieties is $h(1 /(2 m)) G(H(m)-$ $u)-m F$. If active in the market at $u$, the local monopoly offers the number of varieties $m^{m}(u)$ that maximizes the monopoly profit

$$
\pi(m) \equiv h(1 /(2 m)) G(H(m)-u)-m F .
$$

To facilitate comparison of the monopoly outcome with the oligopoly outcome, we will restrict attention to benefit functions $h(x)$ for which the ratio of the marginal expected benefit from shopping locally $v^{\prime}(m)$ and the marginal monopoly price $p^{\prime}(m)$ is a non-increasing function of $m$. In other words, as $m$ increases, the hold-up problem becomes more important. This assumption will insure that the profit function of the monopoly is quasi-concave in $m$.

Assumption 1. The ratio $\frac{v^{\prime}(m)}{p^{\prime}(m)}$ is a non-increasing function of $m$.

This assumption is satisfied for a large class of benefit functions. For if $h(x)=a-t x^{\frac{1}{b}}$, with $b \geq 1$, the ratio is constant and equal to $\frac{b}{b+1}$.

Lemma 3. Under assumption $\square$, the profit function $\pi(m)$ of the monopoly is quasi-concave.

The local monopoly faces only external competition, and can a-priori react to an increase in $u$ by increasing or by decreasing its offer of varieties. Since $H(m)$ is a decreasing function of $m$, while the price $h(1 /(2 m))$ is an increasing function of $m$, offering more surplus to buyers is akin to offering fewer varieties at a lower price. We show that increased external competition induces the monopoly to decrease the number of varieties. 
Indeed, with the monopoly providing net surplus $H(m)-u$ to buyers, the variety elasticity of the demand $G(H(m)-u)$ is equal to $\epsilon(m ; u)=-m H^{\prime}(m) \ell(H(m)-u)$, and therefore the variation of this elasticity with respect to $u$ is equal to $\epsilon_{u}(m, u)=m H^{\prime}(m) \ell^{\prime}(H(m)-u)$, which is positive since $\ell$ is a decreasing function and $H^{\prime}<0$. Hence as $u$ increases, buyers become more sensitive to variety changes, suggesting that the monopoly will want to decrease the number of varieties.

This is apparent from the first order condition defining the optimum for the monopoly. At the covering price $p(m)=h(1 /(2 m))$, the first order condition is

$$
p^{\prime}(m) G(H(m)-u)+p(m) H^{\prime}(m) g(H(m)-u)=F .
$$

The derivative of the left hand side with respect to $u$ is:

$$
\begin{aligned}
-p^{\prime}(m) g(H(m)-u) & -p^{M}(m) H^{\prime}(m) g^{\prime}(H(m)-u) \\
& <-p^{\prime}(m) g(H(m)-u)-p(m) H^{\prime}(m) \frac{g^{2}(H(m)-u)}{G(H(m)-u)} \\
& =-\ell(H(m)-u) F,
\end{aligned}
$$

where the inequality is due to $g^{\prime}<g^{2} / G$, a consequence of log-concavity of $G$, and $-p(m) H^{\prime}(m)>0$; the equality follows from the first order condition. Hence, as $u$ increases, the optimal solution $m^{M}(u)$ decreases. It follows immediately that the surplus to local buyers $H\left(m^{M}(u)\right)$ increases with $u$.

Hence, even under local monopoly that exploits on the custom that has arrived in the local market, an increase in expected buyer surplus in the external market, e.g., resulting from increased competition, brings about an increase in local surplus.

There is a rather obvious limit to the crowding out result. The lowest $m$ that can be chosen by the monopolist is equal to 1 , at which the monopolist provides the maximal surplus to the buyers patronizing the local market. Since the monopolist's profit decreases monotonically with $u$, there exists a large enough value of external competition, such that the monopoly solution when the 
covering price is imposed will coincide with 1 . By continuity, there exists $\bar{u}$ solving :

$$
\left.m^{M}(\bar{u})=1 \& h(1 / 2)\right) G(H(1)-\bar{u})-F=0 .
$$

The following proposition summarizes our discussion.

Proposition 1. Consider a local monopoly that does not commit to prices. As u increases,

(i) The equilibrium number of varieties and the price decrease when $u \leq \bar{u}$.

(ii) Local buyer surplus $H\left(m^{M}(u)\right)$ increases with $u$ when $u \leq \bar{u}$.

(iii) The monopoly exits from the market when $u \geq \bar{u}$.

\subsection{Oligopoly}

If the market structure is that of an oligopoly with free entry, firms face internal competition in addition to the external competition represented by $u$. The derivation of the symmetric price equilibrium in Vickrey-Salop type spatial models is quite standard. We know that two regimes are likely to arise in equilibrium: one where firms fight for the marginal buyer by lowering the price below her maximum willingness to pay in the attempt to cannibalize its immediate neighbors, and another where firms behave as a one-product monopoly on their "natural" market, by setting a price $h(1 /(2 m))$. Thus, contrary to the monopoly, the oligopoly cannot always prevent cannibalization. Indeed, owing to free entry, the regime where there is no inter-variety competition in the oligopoly corresponds to a zero-profit monopoly.

This is also true in our more general specification. There exists a unique cutoff value $m^{*}$ solving ${ }^{\square}$

$$
h\left(1 /\left(2 m^{*}\right)\right)=-\frac{h^{\prime}\left(1 /\left(2 m^{*}\right)\right)}{m^{*}}
$$

such that for lower values of $m$ internal competition is weak enough so that the price is the monopoly price $p(m)=h(1 /(2 m))$ while for values of $m$ greater than the cutoff, internal competition is severe

\footnotetext{
${ }^{5}$ The value is unique because the monopoly price is an increasing function of $m$, while the equilibrium price is a decreasing function of $m$.
} 
and the price is $p(m)=-h^{\prime}(1 /(2 m)) / m<h(1 /(2 m))$. Hence, the surplus to consumers is $H(m)$ for low values of $m$, and is

$$
K(m) \equiv v(m)+\frac{h^{\prime}(1 /(2 m))}{m}
$$

for high values of $m$. These results hold when the market is covered, something that must be true in equilibrium.

The surplus $K(m)$ is an increasing function of $m$ : as $m$ increases, internal competition becomes more severe and firms are to relinquish more surplus to buyers to attract them. ${ }^{\text {[ }}$ At the cutoff value $m^{*}$ surpluses $H\left(m^{*}\right)$ and $K\left(m^{*}\right)$ are equal: the monopoly price for a one-product firm that is protected from internal competition on its natural market is also the equilibrium price when internal competition is taken into account.

Whether the equilibrium value of $m$ is greater or lower than $m^{*}$ is determined by free entry, itself influenced by the value of $u$. As $u$ becomes large, the demand facing the local market decreases and fewer firms should be in the market. This suggests an inverse relationship between external and internal competition: when $u$ increases, fewer firms survive in the local market; internal competition is weak when external competition is important. Below we show formally the existence of a cutoff level $u^{*}$ such that the equilibrium value of $m$ is greater than $m^{*}$ only if $u$ is lower than $u^{*}$.

Finally, the condition for having an active local market under oligopoly is the same as under a monopoly, that is that $u \leq \bar{u}$ as defined in (B) since at $\bar{u}$, a monopoly entering with one variety would make a zero profit.

We summarize this discussion in the following proposition.

Proposition 2. There exists $u^{*}<\bar{u}$ such that

(i) when $u \leq u^{*}$ the equilibrium price is $p^{o}=\left(-h^{\prime}\left(1 /\left(2 m^{O}\right)\right) / m^{O}\right.$ where $m^{o}$ solves the zero profit condition $G(K(m)-u)\left(-\frac{h^{\prime}(1 /(2 m))}{m}\right)-m F=0$. Buyer surplus is $K\left(m^{O}\right)$, an increasing function of $m^{O}$.

(ii) when $u \geq u^{*}$ the equilibrium oligopoly price is $p^{O}=h\left(1 /\left(2 m^{O}\right)\right)$ where $m^{O}$ solves the zero

\footnotetext{
${ }^{6}$ Indeed, $K^{\prime}(m)=2 \int_{0}^{\frac{1}{2 m}} h(x) d x-\frac{1}{m} h\left(\frac{1}{2 m}\right)-\frac{1}{2 m^{3}} h^{\prime \prime}\left(\frac{1}{2 m}\right)-\frac{1}{m^{2}} h^{\prime}\left(\frac{1}{2 m}\right)$, and $K^{\prime}(m)>0$ since $h^{\prime}<0, h^{\prime \prime}<0$ and $2 \int_{0}^{\frac{1}{2 m}} h(x) d x-\frac{1}{m} h\left(\frac{1}{2 m}\right)=\frac{H(m)}{m}>0$.
} 
profit condition $G(H(m)-u) h(1 /(2 m))-m F=0$. Buyer surplus is $H\left(m^{O}\right)$, a decreasing function of $m^{O}$.

(iii) When $u>\bar{u}$ there is no entry into the market.

Given these results, we can characterize further the performance of the two market structures in terms of varieties offered, prices, and surplus given to buyers, as external competition increases. In the competitive region, when $u<u^{*}$, an increase in external competition $u$ triggers a decrease in the number of varieties, but the lower internal competition weakens the price constraint and firms are able to get closer to the willingness to pay of the marginal agent, resulting in a higher price for varieties and thus a lower buyer surplus. External competition creates a negative externality for local consumers.

However, in the monopoly mode region, when $u>u^{*}$, we have the same co-variation of varieties and prices: as $u$ increases, both the number of varieties and the price decrease in response to an increase in external competition. The decrease in internal competition due to a lower number of firms also reduces the willingness to pay of the marginal buyer, but the lower price eventually leads to a higher surplus to local buyers. External competition creates a positive externality for local consumers.

Corollary 1. In response to a local increase in $u$,

- The number of varieties $m^{O}(u)$ decreases.

- If $u \leq u^{*}$, the price $p^{O}$ increases and the surplus to buyers decreases.

- If $u \geq u^{*}$, the price $p^{O}$ decreases and the surplus to buyers increases.

\subsection{When Monopoly improves on Oligopoly for Local Market Perfor- mance}

Given the previous results, it is now simple to return to the questions raised at the outset, on the local reaction to the threat provided by increasing global competition. 
When $u$ is small as generated by little external competition, say, there will be a large number of varieties both under monopoly and oligopoly, hence high expected benefit for buyers from purchasing locally. However, the monopoly appropriates most of the benefit ex-post, since $H(m)$ has limit equal to zero when $m$ becomes large. By contrast, under oligopoly a large number of firms intensifies internal competition and the price $-h^{\prime}(1 /(2 m)) / m$ goes to zero when $m$ becomes large, implying that the surplus $K(m)$ approaches $v(m)$. Therefore for low values of $u$, the local oligopoly provides more surplus to buyers than the monopoly.

By contrast, when $u>u^{*}$, both the monopoly and the oligopoly set a price equal to the expected willingness to pay of the marginal buyer, and provide buyer surplus $H(m)$. However, the monopoly offers fewer varieties than a free entry oligopoly. To see this observe that when $u>u^{*}$, both the monopoly and the zero-profit oligopoly operate along the same profit function, which is shown to be quasi-concave, by Lemma (3). Yet the oligopoly must operate on the decreasing branch of the profit function, whence the monopoly maximizes by setting marginal profit to zero. Since $H(m)$ is a decreasing function the oligopoly provides lesser surplus in spite of offering more variety. Therefore, for $u>u^{*}$, since $H(m)$ is a decreasing function of $m$, the local monopoly provides more surplus to buyers than the oligopoly. We summarize in

Corollary 2. If $u>u^{*}$, the zero-profit oligopoly provides more varieties than the multi-product monopoly. Yet the monopoly provides more buyer surplus.

Note that total buyer surplus including both markets is equal to

$$
G(H(m)-u) H(m)+(1-G(H(m)-u)) u=u+G(H(m)-u)(H(m)-u),
$$

which is the larger the larger $H(m)$, that is the smaller $m$ is. Because an oligopoly with free entry will have more varieties than a monopoly when $u$ is greater than $u^{*}$, the monopoly structure Pareto dominates the oligopoly with free entry.

To summarize, there exists a non-monotonic relationship between the level of external competition and the market structure that maximizes the surplus to consumers. Because $u^{*}$ has been defined as the level of external competition for which $H\left(m^{O}\left(u^{*}\right)\right)=K\left(m^{O}\left(u^{*}\right)\right)$, the level of sur- 
plus provided by an oligopoly is $\max \left\{H\left(m^{O}\left(u^{*}\right)\right), K\left(m^{O}\left(u^{*}\right)\right)\right\}$ attaining a minimum at $u^{*}$. For the monopoly the surplus is $H\left(m^{m}(u)\right)$, increasing in $u$, and we know that $H\left(m^{M}(u)\right)>H\left(m^{O}(u)\right)$ for all $u>u^{*}$. By continuity, it follows that $H\left(m^{M}(u)\right)$ intersects $\max \left\{H\left(m^{O}\left(u^{*}\right)\right), K\left(m^{O}\left(u^{*}\right)\right)\right\}$ at a level $u^{0}<u^{*}$. The surpluses under oligopoly and monopoly coincide at $\bar{u}$ since the monopoly has zero profit there. Figure $\mathbb{0}$ summarizes this discussion.

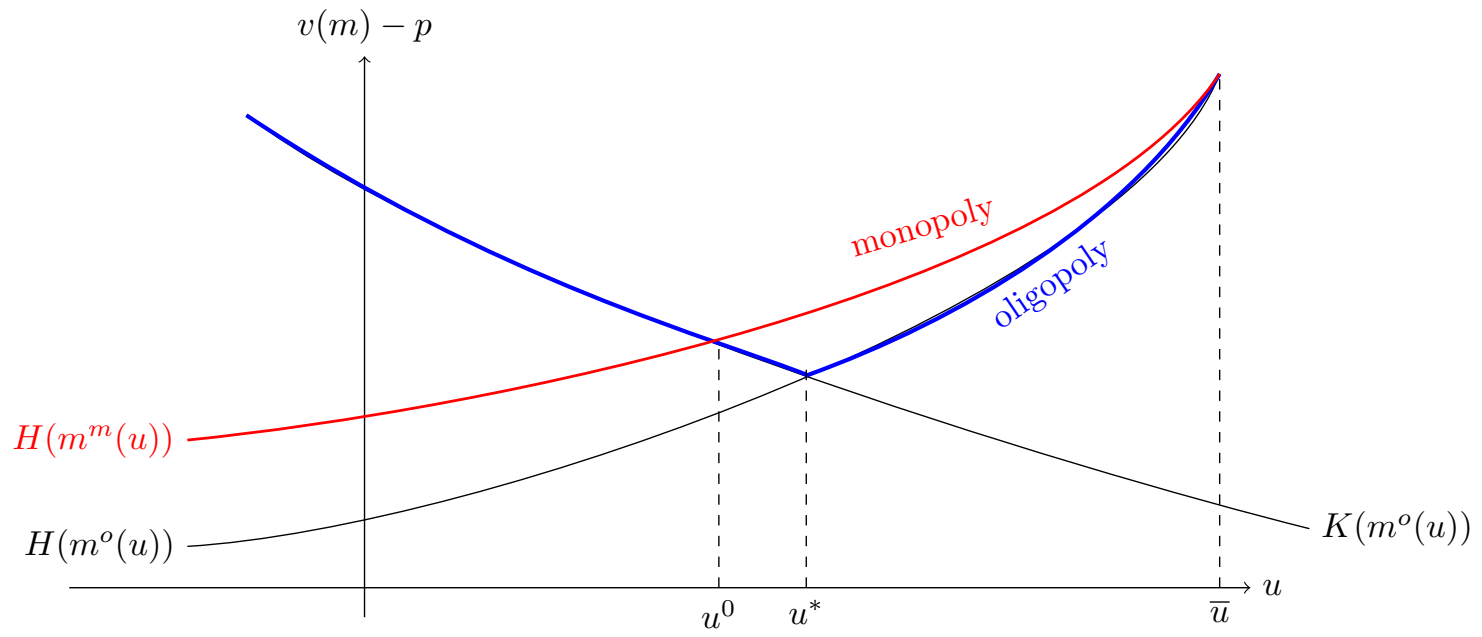

Figure 1: Local Consumer Surplus: Oligopoly vs Monopoly

How do the allocations under the two different market structures compare in terms of total welfare, consisting of the sum of producer and buyer surplus? When the monopoly dominates the oligopoly in terms of local buyer surplus, it also does from a total welfare point of view, as monopoly profits need to be added to buyer surplus. Hence, we have the following result:

Corollary 3. There exists a value of the outside option $u^{0}<u^{*}$ such that local buyer surplus is higher under monopoly if and only if $u>u^{0}$. In this case, total welfare is also higher under monopoly than under oligopoly with free entry.

Note that if the oligopolistic firms could collude after entering the local market, buyers would expect the price to be equal to $h(1 / 2 m)$ and therefore the oligopoly would behave as a zero-profit monopoly, providing surplus $H\left(m^{O}(u)\right)$ to local buyers. In this case, for any level of external competition, a monopoly provides a Pareto dominant form of organization. Hence, the farther 
conduct in an oligopoly with free entry is from unilateral conduct, that is the more likely are collusive outcomes, the less buyers benefit from having little barriers to entry in the local market.

\section{Ex-Post Competition from the External Market}

In the basic model, firms in the local market face competition from the external market only $e x$ ante, when buyers decide which market to patronize. Once consumers have arrived in the local market, competition from the external market is moot. However, competition from the external market can arise essentially from two sources: on one hand, the external market can improve by providing easier access, more varieties, or better inspection opportunities. On the other hand, it can improve by providing varieties at lower prices - in particular the same varieties as the local market. The first source has force primarily ex-ante when buyers decide which market to patronize. The second source has force primarily ex-post, when buyers have learned the preferred variety in the local market, and then have the option to buy that in the external market.

To illustrate the second source by an example, while it is close to impossible to describe ex-ante the match quality a running shoe, it is possible after having tried on different shoes in a brick-andmortar store to identify the model and size that fits best; and then to order the chosen brand and size from the external market. This way the typical buyer exploits the superior inspection services provided by the local market. However, the presence of ex-post price competition may provide price discipline and reduce hold-up in there. Note that this arbitrage option is open to the buyer only for standardized inspection goods that are sold in both markets.

We now add this form of ex-post competition to our model. The possibility for consumers to search locally and shop in the external market provides price discipline locally if, as evidence for internet shopping suggests (e.g. provided by Brynjolfsson and Smith (2000)), prices are lower on the external market, and the cost of accessing the external market is not too large. This price pressure may be present in both monopoly and oligopoly settings, but will have different implications.

Consider first the local multi-product monopoly. We will show that the crowding-out result

\footnotetext{
${ }^{7} \mathrm{~A}$ similar force is exercised by reduced access cost to the external market.
} 
persists if the increase in the outside option is due to a decrease in the price at which the locally inspected good is available in the external market, and that price forces the monopoly to downward adjust its price as well in order to retain its custom.

Here, it is natural to distinguish between a cost $\alpha$ of accessing the local market and a cost $\beta$ of accessing the global one. We assume that $\alpha$ has distribution $G$ (log-concave) and, for simplicity, that $\beta$ is a constant.

The new timing is as follows.

- Buyers learn $\alpha$ and observe the number of varieties in the local market;

- If a buyer shops on the external market, her expected utility is $u=\underline{h}-q-\beta$, where $\underline{h}$ is the expected gross utility obtained if she does not know yet which product to purchase, and $q$ is the price on the external market.

- If the buyer goes to the local market, she learns by selecting from the $m$ varieties the variety that offers the best match $h(x)$;

- she can then buy this variety on the local market and her utility is $h(x)-p-\alpha$, or

- she can buy this variety from the external market and her utility is $h(x)-q-\alpha-\beta$, since she has to pay the access costs to both markets.

Assume that any variety discovered by the consumer locally can be found on the external market. This magnifies the pressure of external competition which is a reasonable depiction for mainstream products (as the evidence in Brynjoltsson et al., 20109 suggests, niche products tend to face less competition than mainstream products.)

With this, there are three options open to buyers:

- Buy from the external market immediately: surplus is $u$;

- Stay in the local market: ex-post surplus is $h(x)-p-\alpha$;

\footnotetext{
${ }^{8}$ Hence $\alpha-\beta$ corresponds to the opportunity $\operatorname{cost} \theta$ of shopping locally in the previous sections of the paper.
} 
- Inspect in the local market but buy from the external market: if the best fit is $h(x)$, her ex-post surplus is $h(x)-q-\beta-\alpha$.

The local market share is the mass of buyers choosing the second option. Note that the choice between the second and the third option depends on whether $\beta$ is larger or smaller than $p-q$ : if $\beta<p-q$, all buyers purchase from the external market. Hence for buyers to shop locally at all, we need

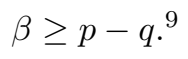

This constraint is a simple representation of ex-post price competition from the external market, that depends on the price differential and the cost of going on the external market. Clearly, in an equilibrium with positive entry into the local market this constraint must be satisfied. From an ex-ante perspective, the buyers who decide to go to the local market are those whose type is

$$
\alpha-\beta \leq \tilde{\theta}(m, p(m), u)=v(m)-p(m)-u
$$

where $p(m)$ is the price that buyers anticipate in the local market.

In equilibrium buyers anticipate a price

$$
p(m)=\min \left\{\beta+q, h\left(\frac{1}{2 m}\right)\right\} .
$$

Once the buyers show up in the local market, the monopolist chooses the price. The problem is then

$$
\max _{m} p(m) G(\tilde{\theta}(m, p(m), u))-m F
$$

If the solution $m^{M}(u)$ in Proposition $\mathbb{W}$ is in the region $\left\{m: \beta+q>h\left(\frac{1}{2 m}\right)\right\}$, the monopoly will

\footnotetext{
${ }^{9}$ In this case, no consumers patronizing the local market will buy ex-post from the external market; this is due to the assumption that the cost $\beta$ is common to all consumers. A non-degenerate distribution of the cost $\beta$ would tend to induce the self-selection of consumers: the high $\beta$ consumers would remain in the local market whence the low $\beta$ consumers would move on purchasing in the global one.
} 
choose the same number of varieties as before. Ex-post competition is ineffective. However, if the solution is in the region $\left\{m: \beta+q \leq h\left(\frac{1}{2 m}\right)\right\}$, consumers anticipate a price of $\beta+q$ when going to the local market. Then their expected surplus is $v(m)-(\beta+q)-\alpha$. Alternatively, if they decide to go directly to the external market, their surplus is $\underline{h}-(\beta+q)$ because they do not benefit from the search result in the local market. Therefore, they go to the local market if $\alpha \leq v(m)-\underline{h}$, and the marginal type to go to the local market is $\tilde{\theta}(m, \beta+q, u)=v(m)-\underline{h}$. Hence, the monopoly maximizes $(\beta+q) G(v(m)-\underline{h})-m F$ and the first order condition is

$$
(\beta+q) v^{\prime}(m) g(v(m)-\underline{h})=F .
$$

If ex-post competition is induced by a decrease in the expected total price $\beta+q$, we obtain by using an envelope argument that

$$
\frac{d m^{M}}{d(\beta+q)}=v^{\prime}\left(m^{M}\right) g\left(v\left(m^{M}\right)-\underline{h}\right)>0
$$

Hence, varieties in the monopoly unambiguously decrease as $\beta+q$ decreases, so the result of crowding out of local varieties we obtained in the base model is upheld.

Let us now turn to the local oligopoly structure. Recall that by the free entry condition, the variation of the profit $(\beta+q) G(v(m)-\underline{h})-m F$ in $m$ must be negative. Hence, by the implicit function theorem, $\frac{d m^{O}}{d(\beta+q)}$ has the same sign as $G(v(m)-\underline{h})$ and we have the same crowding out effect: as ex-post competition increases due to a decrease of $\beta+q$, the free-entry oligopoly will offer fewer varieties.

In the basic model, when $u<u^{*}$, local buyers were facing a price $p(m)=-h^{\prime}(1 / 2 m) / m$. With the possibility to search locally but to buy in the external market, that changes to

$$
p(m)=\min \left\{\beta+q,-h^{\prime}(1 / 2 m) / m\right\} .
$$

Starting at a low level of $u$, any increase in $u$ that is generated by a decrease in the external market price level $q$ reduces the local custom, and with it the number of oligopolists active in 
the local market. This leads the local equilibrium price $p(m)=-h^{\prime}(1 / 2 m) / m$ to increase, which eventually brings about $\beta+q$ as the price binding locally.

In the basic model with ex-ante competition only, the oligopoly behaves as a zero profit monopoly but provides lower surplus to buyers than a monopoly as long as $u \geq u^{*}$. This situation dramatically changes with ex-post competition. Starting from the equilibrium prices $p^{M}(u), p^{O}(u)$ when there is no ex-post competition, if eventually $\beta+q$ turns smaller than these prices, it must be the case that an oligopoly performs better than a monopoly. Indeed, let $\pi(m):=(\beta+q) G(v(m)-\underline{h})-m F$ be the total industry profit. As in the basic model, in a free-entry oligopoly the equilibrium number of varieties satisfies $\pi^{\prime}\left(m^{O}\right)<0$, but in multi-product monopoly it is determined by $\pi^{\prime}\left(m^{M}\right)=0$. Therefore the free-entry number of varieties $m^{O}$ must be larger than the number of varieties $m^{M}$ chosen by multi-product monopolist. Furthermore, consumer surplus $v(m)-(\beta+q)$ is larger in the free-entry oligopoly. The reason is that in contrast to the base model, the buyer's opportunity to purchase the variant in the external market at price $\beta+q$ is binding in both market structures.

We summarize this discussion in the following proposition.

Proposition 3. If the external market price $\beta+q$ is binding in the local market, then

(i) any increase in u generated by a decrease in $\beta+q$ reduces varieties in both market structures

(ii) the multi-product monopoly offers fewer variants than the free-entry oligopoly

(iii) buyer surplus is higher under free-entry oligopoly.

\section{Conclusion}

We have analyzed the effect of improved opportunities in an external market, and therefore decreased custom in a local market, on the choice of varieties and price therein under both, local multi-product monopoly and local oligopoly. Towards this, we develop a one-stop shopping search version of the classical Vickrey-Salop differentiated-products-model for the local market, and contribute to theory by developing, within this framework, a tractable model of horizontally differentiated multi-product monopoly, that in particular allows for the endogenous determination of the 
number of variants offered by that monopoly.

Focusing first on pure ex-ante competition involving the buyers' decision of patronizing one of the two markets, we show first that increased external competition reduces local variety no matter the local market structure, and no matter the level of expected buyer utility provided by the external market. Our other results, however, differ by both. If the threat provided from external competition to the local markets is low, competition under free entry oligopoly softens and with it, buyer surplus decreases with increasing external competition, but still leads to higher local buyer surplus than local multi-product monopoly. If the threat from external competition is high, the opposite happens: whereas the surplus to local buyers now also increases under oligopoly, the local multi-product monopolist provides more local buyer surplus.

This pattern still changes when we add ex-post competition, by which buyers, after having exploited the superior search and inspection opportunities in the local market, have the possibility to turn to the external market to buy the chosen variant at a lower price. When local markets are constrained by low price offers from the external market, the free-entry oligopoly offers more variants and higher buyer surplus than the multi-product monopoly. However, this outcome is restricted to the case in which standardized commodities are offered in both markets, allowing buyers to buy at the lowest price in either market.

What are the responses suggested by our analysis to the policy questions raised, and the examples given in the introduction? The most clear cut responses are in terms of competition policy and relate very directly to both types of examples given there. The first response is methodological: In the light of emerging external markets, the product, and geographical market definitions customary in competition policy are no longer applicable. They need reconsideration, in particular to include the new market channel(s).

The second set of response is policy specific: (i) Do never allow for local concentration when standardized commodities are involved. (ii) When non-standardized commodities are involved, do not allow for concentration, in particular mergers in local markets when external competition is low. By contrast, be lenient towards local concentration when external competition is high. The general reason for the latter is that the firms active in concentrated markets are willing and able to 
better internalize the effects of their actions on the local custom, and with this better contribute not only to local, but to general welfare. These policy conclusions are clear and strong. The obvious challenge is to seek the empirical identification of the regimes under which external competition is low vs. high. That must be left to the empirical analyst.

\section{A Appendix}

\section{Proof of Lemma 1}

Let $p<h(1 /(2 m))$. Then the market is covered, and the monopolist could increase its price up to at least $h(1 /(2 m))$ without losing customers. Suppose now that $p>h(1 /(2 m))$. Then the monopolist' ex-ante total expected profit is

$$
\pi(m)=2 m h^{-1}(p) G\left(2 m \int_{0}^{h^{-1}(p)}(h(x)-p) d x-u\right) p-m F
$$

and we assume that $\pi(m) \geq 0$.

Differentiation yields

$$
\pi^{\prime}(m)=\frac{\pi(m)}{m}+4 m h^{-1}(p)\left(\int_{0}^{h^{-1}(p)}(h(x)-p) d x\right) g\left(2 m \int_{0}^{h^{-1}(p)}(h(x)-p) d x-u\right) p
$$

which is positive. Hence the monopoly increases the number of varieties offered as long as $p>$ $h(1 /(2 m))$, proving that the market is covered. 


\section{Proof of Lemma 2}

Simple computations lead to

$$
\begin{aligned}
H(m) & >0,1<m<\infty \\
\lim _{m \rightarrow \infty} H(m) & =0 \\
H^{\prime}(m) & =2 \int_{0}^{\frac{1}{2 m}} h(x) d x-\frac{1}{m} h\left(\frac{1}{2 m}\right)+\frac{1}{2 m^{2}} h^{\prime}\left(\frac{1}{2 m}\right) \\
H^{\prime \prime}(m) & =-\frac{1}{2 m^{3}}\left(h^{\prime}\left(\frac{1}{2 m}\right)+\frac{1}{2 m} h^{\prime \prime}\left(\frac{1}{2 m}\right)\right) .
\end{aligned}
$$

Since $h$ is decreasing, $h(x)>h\left(\frac{1}{2 m}\right)$ when $x \in\left(0, \frac{1}{2 m}\right)$, hence ( $(\mathbb{)})$ follows. Since $h$ is decreasing

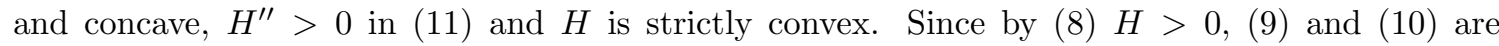
compatible with $H$ convex only if $H^{\prime}(m)<0$.

\section{Proof of Lemma 3}

Let

$$
\pi(m):=p(m) G(H(m)-u)-m F .
$$

and consider $m^{*}$ such that $\pi^{\prime}\left(m^{*}\right)=0$, a condition which can be rewritten as

$$
p^{\prime}\left(m^{*}\right) G\left(H\left(m^{*}\right)-u\right)\left[1+\frac{H^{\prime}\left(m^{*}\right)}{p^{\prime}\left(m^{*}\right)} p\left(m^{*}\right) \ell\left(H\left(m^{*}\right)-u\right)-\frac{F}{p^{\prime}\left(m^{*}\right) G\left(H\left(m^{*}\right)-u\right)}\right]=0,
$$

and since $p^{\prime}(m) H(m)$ is positive,

$$
1=-\frac{H^{\prime}\left(m^{*}\right)}{p^{\prime}\left(m^{*}\right)} p\left(m^{*}\right) \ell\left(H\left(m^{*}\right)-u\right)+\frac{F}{p^{\prime}\left(m^{*}\right) G\left(H\left(m^{*}\right)-u\right)} .
$$

$\frac{F}{p^{\prime}\left(m^{*}\right) G(H(m)-u)}$ is an increasing function of $m$; by log-concavity of $G, \ell(H(m)-u)$ is also an increasing function of $m$, and we know that $p(m)$ is an increasing function of $m$. Now, $-\frac{H^{\prime}(m)}{p^{\prime}(m)}=$ $1-\frac{v^{\prime}(m)}{p^{\prime}(m)}$ is increasing in $m$ because by assumption $\mathbb{W}, \frac{v^{\prime}(m)}{p^{\prime}(m)}$ is a decreasing function of $m$ and by Lemma 『, $v^{\prime}(m)<p^{\prime}(m)$. This proves that if $\pi^{\prime}\left(m^{*}\right)=0$ then for any $m,\left(m-m^{*}\right)\left(\pi^{\prime}(m)-\pi^{\prime}\left(m^{*}\right)\right)$ 
is negative, ensuring quasi-concavity.

\section{References}

Anderson, S. And R. Renault (2006): "Advertising Content," The American Economic Review, 96, 93-113.

Anderson, S. P. And A. De Palma (2000): "From Local to Global Competition," European Economic Review, 44, 423-448.

Armstrong, M. And J. Vickers (2018): "Multiproduct Pricing Made Simple," Journal of Political Economy, 126, 1445-1471.

Balasubramanian, S. (1998): "Mail versus Mall: A Strategic Analysis of Competition between Direct Marketers and Conventional Retailers," Marketing Science, 17, 181-195.

Bouckaert, J. (2000): "Monopolistic Competition With a Mail Order Business," Economics Letters, 66, 303-310.

Brynjolfsson, E., Y. Hu, and M. Rahman (2009): "Battle of the Retail Channels: How Product Selection and Geography Drive Cross-Channel Competition," Management Science, 55, 1755-1765.

Brynjolfsson, E. And M. Smith (2000): "Frictionless Commerce? A Comparison of Internet and Conventional Retailers," Management Science, 46, 563-585.

Chen, Y. And M. Riordan (2008): "Price-increasing Competition," RAND Journal of Economics, 39, 1042-1058.

Deneckere, R. J. And M. Rothschild (1992): "Monopolistic Competition and Preference Diversity," The Review of Economic Studies, 59, 361-373.

Forman, C., A. Ghose, And A. Goldfarb (2009): "Competition Between Local and Electronic Markets: How the Benefit of Buying Online Depends on Where You Live," Management Science, 55, 47-57.

George, L. (2009): "National Television and the Market for Local Products: The Case of Beer," The Journal of Industrial Economics, 57, 85-111.

JiA, P. (2008): "What Happens When Wal-Mart Comes to Town: An Empirical Analysis of the Discount Retailing Industry," Econometrica, 76, 1263-1316.

Johnson, J. And D. Myatt (2006): "On the Simple Economics of Advertising, Marketing, and Product Design," American Economic Review, 96, 758-784.

Michael, S. (1994): "Competition in Organizational Form: Mail Order Versus Retail Stores, 1910-1940," Journal of Economic Behavior and Organization, 23, 269-286.

Nocke, V. And N. Schutz (2018): "Multiproducgt-firm Ologopoly: An Aggregative Games Approach," Econometrica, 86, 523-557.

Pozzi, A. (2013): "The effect of Internet distribution on brick-and-mortar sales," RAND Journal of Economics, 4, 360-390.

Rhodes, A. (2015): "Multiproduct Retailing," Review of Economic Studies, 82, 360-390. 
Rhodes, A. And J. Zhou (2016): "Consumer Search and Retail Market Structure," Toulouse School of Economics, mimeo.

Salop, S. C. (1979): "Monopolistic Competition With Outside Goods," The Bell Journal of Economics, 10, 141-156.

Schulz, N. And K. O. Stahl (1996): "Do Consumers Search for the Highest Price? Oligopoly Equilibrium and Monopolistic Optimum in Differentiated Products Markets," RAND Journal of Economics, 27, 544562 .

Spence, M. (1975): "Monopoly, Quality, and Regulation," The Bell Journal of Economics, 6, 417-429.

Stahl, K. O. (1982): "Consumer Search and the Spatial Distribution of Retailing," Journal of Industrial Economics, 31, 97-114.

Wolinsky, A. (1984): "Product Differentiation with Imperfect Information," Review of Economic Studies, $51,53-61$.

Zноu, J. (2014): "Multiproduct Search and theJoint Search Effect," thge American Economic Review, 104, 2918-2939. 